\title{
Study on the Stereoregularity of Polyacrylonitrile Produced by Precipitation Polymerization in Supercritical $\mathrm{CO}_{2}$
}

\author{
Xin-Rong Teng, ${ }^{\dagger}$ Xue-Chao Hu, ${ }^{*}$ and Hui-Li SHAO* \\ Material Science and Engineering College, Tong Ji University, Shanghai 200092, China \\ ${ }^{*}$ College of Material Science and Engineering, Dong Hua University, Shanghai 200051, China
}

(Received January 29, 2002; Accepted May 21, 2002)

\begin{abstract}
The triad and pentad tacticities of PAN obtained by precipitation polymerization in supercritical carbon dioxide, using AIBN as initiator, (hereafter, referred as $\mathrm{CO}_{2}$-PAN) were analyzed by ${ }^{13} \mathrm{C} \mathrm{NMR}$ and IR method. The pentad tacticities of $\mathrm{CO}_{2}$-PAN from the intensities of cyano peaks were examined by statistical methods. It was found that $\mathrm{CO}_{2}$-PAN was completely random in stereoregularity, and the sequence distributions of it obey Bernoulli statistics. Compared with the aqueous phase suspension polymerization of AN, using AIBN as initiator, (hereafter, referred as SPAN) and aqueous phase precipitation polymerization of AN, using redox type initiator, (hereafter, referred as R-PAN), it was found isotacticity of $\mathrm{CO}_{2}$-PAN was lower than those of S-PAN and R-PAN, although the three kinds of PAN were all random in stereoregularity. The reason is probably due to the different polar property of solvent used. The relation between IR data and stereoregularity of PAN has also been used to calculate the isotactic triad units of $\mathrm{CO}_{2}-\mathrm{PAN}$, the result is accordant with the ${ }^{13} \mathrm{C}$ NMR method used.

KEY WORDS Supercritical $\mathrm{CO}_{2} /$ Polyacrylonitrile $/{ }^{13} \mathrm{C}$ Nuclear Magnetic Resonance (NMR) /

Stereoregularity / Statistics Method / Isotacticity / IR Spectrum /
\end{abstract}

With respect to the intense advantages in environmental friendly, low cost, and nonflammable alternatively to the aqueous and organic solvents, recently, the supercritical $\mathrm{CO}_{2}$ has been broadly applied to make industrial polymers including the PAN. ${ }^{1-6}$ As reported, $\mathrm{CO}_{2}$ can play such a role similar to a hydrocarbon solvent hence to benefit for dissolving small molecules and exhibiting high solubility for monomer. ${ }^{7}$ At present time, polymerization of acrylonitrile (AN) in the presence of $\mathrm{CO}_{2}$ has been reported by some researchers. 5,6 Of which, Shiho and DeSimone ${ }^{5}$ have carried out the dispersion polymerization of acrylonitrile in carbon dioxide using a block copolymer as a stabilizer. They discussed the effects of reaction conditions (i.e., the concentration of acrylonitrile and stabilizer, reaction pressure) on the resulting size of the PAN particles. In our lab, the precipitation polymerization of AN in supercritical $\mathrm{CO}_{2}$ has also been successfully conducted. We discussed molecular weight and spinnability ${ }^{8}$ as well as molecular weight distribution ${ }^{9}$ of obtained PAN product. As an extension of the previous study, ${ }^{8,9}$ recently, the tacticity of PAN, prepared using AIBN as initiators by precipitation polymerization in supercritical $\mathrm{CO}_{2}$, was investigated by ${ }^{13} \mathrm{C}$ NMR and IR method. We think the detailed analysis on tacticity of $\mathrm{CO}_{2}$-PAN will be very helpful for a better understanding of $\mathrm{CO}_{2}-$ PAN's polymerization mechanism and its characteristics molecular properties in solution. So far, many studies on the stereoregularity of polyacrylonitrile (PAN) have been carried out by ${ }^{13} \mathrm{C}$ NMR. ${ }^{10-14}$ It is generally believed that the $\mathrm{CN}$ carbon peak region roughly separates into three envelopes corresponding to I (isotactic), $\mathrm{H}$ (heterotactic), S (syndiotactic) triads and each envelope splits in a very small chemical shift range into 3 or 4 peaks due to pentad sequences. ${ }^{12}$ Here, we want to evaluate the pentad tacticity of the $\mathrm{CO}_{2}$-PAN from the intensities of cyano peaks splitting into ten peaks in ${ }^{13} \mathrm{C}$ NMR spectra, and tried to examine these values by statistical models.

In order to better understand the tacticity of $\mathrm{CO}_{2}-$ PAN $\left(M_{\mathrm{w}}=1.2 \times 10^{5}\right)$, in this paper, we tried to use the S-PAN (aqueous phase suspension polymerization, using AIBN as initiator, in radical mechanism, $M_{\mathrm{w}}=8.2 \times 10^{5}$ ) and R-PAN (using the redox type initiator in aqueous media, $M_{\mathrm{W}}=1.6 \times 10^{5}$ ) for comparison. Notably, all the data for R-PAN is quoted from Kamide. ${ }^{11,12}$

\section{EXPERIMENTAL}

\section{Polymer Sample}

$\mathrm{CO}_{2}$-PAN Was Prepared in the Following Manner. The precipitation polymerization was carried out using a $500 \mathrm{~mL}$ autoclave, the whole system is outlined in Figure 1.

After adding AN and AIBN, the autoclave was covered to start the polymerization. First, a short time flow of $\mathrm{CO}_{2}$ prior to the rising of the temperature was done

${ }^{\dagger}$ To whom correspondence should be addressed (E-mail: Sheila.teng@263.net). 


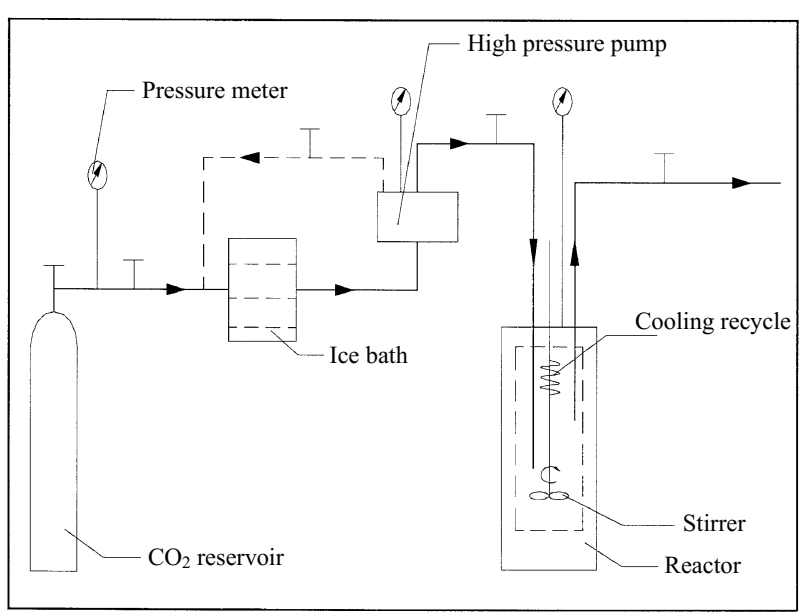

Figure 1. Supercritical $\mathrm{CO}_{2}$ polymerization system for PAN.

to make the autoclave filled with only the employed $\mathrm{CO}_{2}$. With the temperature increasing, the piston pump was started to fit the need of $\mathrm{CO}_{2}$ flowing into autoclave continuously to raise the pressure to pre-desired level. Once the pre-desired temperature and pressure approached, the reaction started and the stir was turn on. During reaction, cooling water circulator, attached to an internal coil, was used to control the temperature. After reaction, by cooling the reactors to room temperature and venting the $\mathrm{CO}_{2}$ slowly, the powder PAN thus was collected with a glass cell. In this paper, the reaction conditions of $\mathrm{CO}_{2}-\mathrm{PAN}$ used were as follows: acrylonitrile was added with $12 \%(\mathrm{w} / \mathrm{v} \%$, AN $\left.(\mathrm{g}) / \mathrm{CO}_{2}(\mathrm{~mL})\right)$, AIBN added was about $1.25 \%$ of the monomer, the temperature was remained at $65 \pm 3^{\circ} \mathrm{C}$, the $\mathrm{CO}_{2}$ pressure is kept at $24 \pm 1 \mathrm{MPa}$ and the total reaction time was pre-set as $15 \mathrm{~h}$.

S-PAN was prepared by using AIBN as initiator, in aqueous media, Poly (vinyl alcohol) (PVA, DP $=1750$ ) as suspending agent, reaction temperature $55-57^{\circ} \mathrm{C}$.

The weight-average molecular weight was determined by the GPC method.

\section{${ }^{13}$ C NMR Measurement}

${ }^{13} \mathrm{C}$ NMR measurements were made on a DMX500 spectrometer under the following operating conditions: Polymer concentration $5 \mathrm{wt} \%$, temperature $300 \mathrm{~K}$, deuterated dimethyl sulfoxide (DMSO- $d_{6}$ ) was chosen as a solvent.

The integrated peaks were estimated as follows: The NMR spectra with integrated curves (Figure 2), was distributed to three peoples in our lab for analysis. They independently integrated curves by their own judgment for three times. The data reported were in good agreement within reading errors and finally the averaged values were taken in this work.

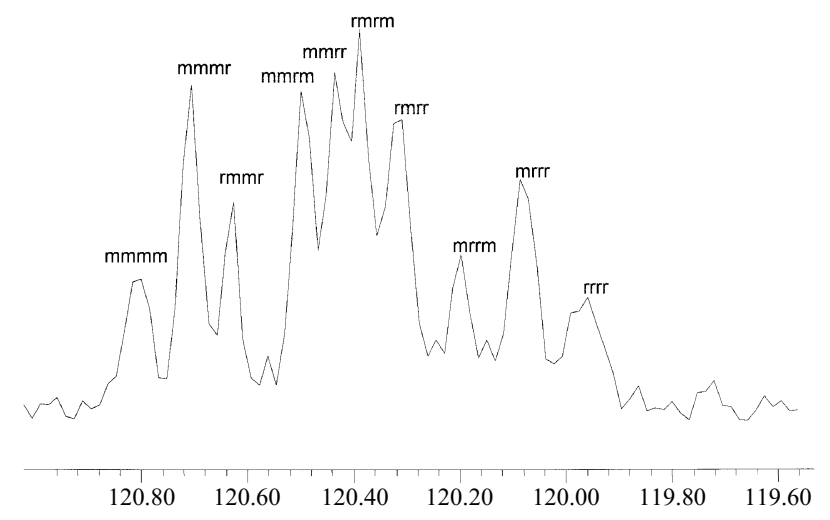

Figure 2. ${ }^{13} \mathrm{C}$ NMR spectra of $\mathrm{CO}_{2}$-PAN for $\mathrm{CN}$-carbon region.

Table I. Peak assignment of $\mathrm{CN}$ carbon for $\mathrm{CO}_{2}-\mathrm{PAN}, \mathrm{S}-\mathrm{PAN}$,

\begin{tabular}{|c|c|c|c|c|}
\hline Base & Pentad & $\mathrm{CO}_{2-}^{-}$ & S-PAN/ & ${ }^{\mathrm{a}} \mathrm{R}-\mathrm{PAN} /$ \\
\hline \multirow[t]{2}{*}{ Triad } & Sequence & PAN/DMSO- $d_{6}$ & DMSO- $d_{6}$ & DMSO- $d_{6}$ \\
\hline & & $\begin{array}{c}\mathrm{ppm} \\
\end{array}$ & $\overline{\mathrm{ppm}}$ & $\overline{\mathrm{ppm}}$ \\
\hline \multirow{3}{*}{ I } & $\mathrm{mmmm}$ & 120.797 & 119.754 & 119.95 \\
\hline & $\mathrm{mmmr}$ & 120.701 & 119.678 & 119.87 \\
\hline & $\mathrm{rmmr}$ & 120.623 & 119.603 & 119.80 \\
\hline \multirow{4}{*}{$\mathrm{H}$} & mmrm & 120.476 & 119.468 & 119.65 \\
\hline & $\mathrm{mmrr}$ & 120.427 & 119.398 & 119.60 \\
\hline & rmrm & 120.384 & 119.376 & 119.56 \\
\hline & rmrr & 120.306 & 119.325 & 119.50 \\
\hline \multirow{3}{*}{$\mathrm{S}$} & mrrm & 120.194 & 119.204 & 119.39 \\
\hline & mrrr & 120.066 & 119.144 & 119.29 \\
\hline & rrrr & 119.957 & 119.021 & 119.20 \\
\hline
\end{tabular}

${ }^{a}$ All the data for R-PAN is quoted from Kamide. ${ }^{11}$

\section{IR Measurement}

The Nicolet Nexus-670 IR spectrophotometer were used. The $\mathrm{KBr}$ disk was mainly used for powders.

\section{RESULTS AND DISCUSSION}

Figure 2 shows the ${ }^{13} \mathrm{C}$ NMR spectra of $\mathrm{CN}$ carbon regions for $\mathrm{CO}_{2}-\mathrm{PAN}$. $\mathrm{CN}$ carbon peaks in the range 120-121 ppm are approximately divided into three envelopes and each envelope is further split into 3 or 4 peaks. The three envelopes is considered to reflect the triad tacticity of PAN, and the fact that each envelope consists of 3 or 4 peaks is related the pentad tacticity of PAN.

Table I show the comparison of chemical shift of CN carbon for $\mathrm{CO}_{2}$-PAN, S-PAN, and R-PAN. The chemical shift of all the $\mathrm{CN}$ carbon peaks in the $\mathrm{CO}_{2}$-PAN system appears by $0.94-1.0 \mathrm{ppm}$ higher than those in S-PAN and 0.75-0.84 ppm higher than those in R-PAN. The smaller difference in the chemical shifts of the three kinds of PAN can be explained by the experi- 
Table II. Comparison of the observed pentad fractions for $\mathrm{CO}_{2}-\mathrm{PAN}, \mathrm{S}-\mathrm{PAN}$, and R-PAN with those calculated by Bernoulli and Markov statistics

\begin{tabular}{|c|c|c|c|c|c|c|c|c|}
\hline \multirow[b]{2}{*}{$\begin{array}{c}\text { Pentad } \\
\text { Sequence }\end{array}$} & \multicolumn{3}{|c|}{$\mathrm{CO}_{2}$-PAN } & \multicolumn{3}{|c|}{ S-PAN } & \multicolumn{2}{|c|}{${ }^{\mathrm{f}} \mathrm{R}-\mathrm{PAN}$} \\
\hline & Observed & $\frac{\text { Bernoulli }}{\text { Triad }}$ & $\begin{array}{l}\text { 1st-order } \\
\frac{\text { Markov }}{\text { Triad }} \\
\text { method }^{\mathrm{b}}\end{array}$ & Observed & $\frac{\text { Bernoulli }}{\text { Triad }}$ & $\begin{array}{l}\text { 1st-order } \\
\frac{\text { Markov }}{\text { Triad }} \\
\text { method }^{\mathrm{d}}\end{array}$ & Observed & 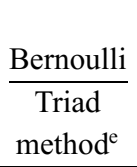 \\
\hline $\mathrm{mmmm}$ & 0.014 & 0.023 & 0.023 & 0.078 & 0.073 & 0.076 & 0.077 & 0.073 \\
\hline $\mathrm{mmmr}$ & 0.085 & 0.073 & 0.073 & 0.128 & 0.135 & 0.133 & 0.125 & 0.134 \\
\hline $\mathrm{rmmr}$ & 0.054 & 0.057 & 0.058 & 0.063 & 0.062 & 0.062 & 0.068 & 0.062 \\
\hline mmrm & 0.058 & 0.073 & 0.075 & 0.13 & 0.134 & 0.127 & 0.125 & 0.134 \\
\hline $\mathrm{mmrr}$ & 0.103 & 0.113 & 0.113 & 0.127 & 0.124 & 0.128 & 0.097 & 0.125 \\
\hline rmrm & 0.12 & 0.113 & 0.118 & 0.114 & 0.124 & 0.114 & 0.149 & 0.125 \\
\hline rmrr & 0.2 & 0.177 & 0.179 & 0.114 & 0.116 & 0.114 & 0.129 & 0.116 \\
\hline mrrm & 0.092 & 0.057 & 0.057 & 0.102 & 0.062 & 0.062 & 0.055 & 0.062 \\
\hline mrrr & 0.144 & 0.177 & 0.173 & 0.09 & 0.116 & 0.122 & 0.112 & 0.116 \\
\hline rrrr & 0.123 & 0.138 & 0.131 & 0.054 & 0.054 & 0.062 & 0.065 & 0.054 \\
\hline$\lambda$ & 0.95 & & & 1.13 & & & 0.99 & \\
\hline$\delta \times 10^{3}$ & & 6.0 & 5.66 & & 5.64 & 5.93 & & 4.39 \\
\hline
\end{tabular}

mental error at least in part. This suggests that stereochemical configuration of the three kinds of PAN is capable to being compared.

\section{Analysis of Polymerization Mechanism through Se- quence Distributions of PAN Chain}

The meso and racemic sequence distribution of the polymer chain is a straightforward reflection of characteristic feature of the polymerization reaction by which polymer is synthesized. ${ }^{15}$ We calculated the fractions of pentad sequence of $\mathrm{CO}_{2}-\mathrm{PAN}, \mathrm{S}-\mathrm{PAN}$, and RPAN in DMSO- $d_{6}$ by assuming Bernoulli or first-order Markov statistics ${ }^{16,17}$ (Table II). For this, the following fundamental parameters should be evaluated in advance: In Bernoulli statistics, $P_{\mathrm{m}}$-probability of meso arrangement; In the first-order Markov statistics, $P_{\mathrm{m} / \mathrm{m}^{-}}$ probabilities that a monomer unit adds to a meso sequence in a meso arrangement, and $P_{\mathrm{r} / \mathrm{m}}$-probabilities of a monomer unit adds to meso sequence in a racemic arrangement, and $P_{\mathrm{m} / \mathrm{r}}$-probabilities of a monomer unit adds to a racemic sequence in a meso arrangement.

$P_{\mathrm{m}}, P_{\mathrm{r} / \mathrm{m}}$, and $P_{\mathrm{m} / \mathrm{r}}$ can be readily derived using the isotactic $(\mathrm{I})$, heterotactic $(\mathrm{H})$, and syndiotactic $(\mathrm{S})$ triad fractions. ${ }^{17}$

$$
\begin{gathered}
P_{\mathrm{m}}=\mathrm{I}^{1 / 2} ; \quad P_{r}=1-P_{\mathrm{m}} \\
P_{\mathrm{r} / \mathrm{m}}=\mathrm{H} /(2 \mathrm{I}+\mathrm{H}) ; \quad P_{\mathrm{m} / \mathrm{m}}=1-P_{\mathrm{r} / \mathrm{m}} \\
P_{\mathrm{m} / \mathrm{r}}=\mathrm{H} /(2 \mathrm{~S}+\mathrm{H}) ; \quad P_{\mathrm{r} / \mathrm{r}}=1-P_{\mathrm{m} / \mathrm{r}}
\end{gathered}
$$

The summation of the experimentally determined fractions of mmmm, mmmr, and rmmr was used for I fraction, the summation of the fractions of mmrm, mmrr, rmrm, and rmrr for the $\mathrm{H}$ fraction and the summation of the fractions of mrrm, mrrr, and rrrr for the $\mathrm{S}$ fraction. The method to obtain the parameters $P_{\mathrm{m}}, P_{\mathrm{r} / \mathrm{m}}$, and $P_{\mathrm{m} / \mathrm{r}}$ from the observed triad fractions is simply referred to as the triad method.

For the Bernoulli statistics, a parameter $\lambda$ was introduce by

$$
\lambda=4 \mathrm{IS} / \mathrm{H}^{2}
$$

When $\lambda$ approaches to 1 , the triad sequence of polymer obeys Bernoulli statistics. The $\lambda$ values for $\mathrm{CO}_{2}-\mathrm{PAN}$, S-PAN, and R-PAN calculated are shown in Table II.

Further, in order to judge which statistics are more reasonable to explain the pentad sequence of PAN, a parameter $\delta$, defined by

$$
\delta=\left\{\sum_{i}^{N}\left(X_{i, \mathrm{obs}}-X_{i, \mathrm{calc}}\right)^{2}\right\}^{1 / 2} / N(1)
$$

is introduced. ${ }^{11}$ Where $X_{i, \mathrm{obs}}$, and $X_{i, \text { calc }}$ are the experimental and calculated fractions for a specific pentad sequence, respectively, and $N$ is the total number of pentad sequence(i.e., 10). $\delta$ values obtained by the different statistics methods are shown in Table II.

The second, 5th and 8th columns of Table II list the fractions of various pentad sequences of $\mathrm{CO}_{2}-\mathrm{PAN}$, $\mathrm{S}-\mathrm{PAN}$, and R-PAN in DMSO- $d_{6}$ respectively, determined experimentally from the integral curve under the corresponding NMR peaks. In the third, 6th and 9th columns of Table II, the theoretical fractions of the pentad sequence for $\mathrm{CO}_{2}$-PAN, S-PAN, and R-PAN evaluated by the Bernoulli statistics are compiled. In the 
Table III. Comparison of triad isotacticity of $\mathrm{CO}_{2}-\mathrm{PAN}$ calculated by $\mathrm{IR}$ and ${ }^{13} \mathrm{C}$ NMR methods

\begin{tabular}{cccc}
\hline & IR method & ${ }^{13} \mathrm{C}$ NMR method \\
\hline & $1230 \mathrm{~cm}^{-1}$ & $1250 \mathrm{~cm}^{-1}$ & \\
Integrated Baseline $\left(\mathrm{cm}^{-1}\right)$ & $(1286.308,1189.884)$ & $(1286.308,1189.884)$ & \\
Integrated Region $\left(\mathrm{cm}^{-1}\right)$ & $(1232.311,1189.884)$ & $(1286.308,1232.311)$ & \\
Integrated Area & 54.016 & 131.269 & \\
Calculation & ${ }^{\mathrm{a}} X=(Y-0.21) / 0.51$ & $\mathrm{mmmm}+\mathrm{mmmr}+\mathrm{rmmr}$ \\
Isotactic triad units & 0.160 & 0.153 \\
\hline${ }^{\mathrm{a} Y=54.016 /(54.016+131.269) .}$
\end{tabular}

4th and 7th columns, the theoretical fractions of pentad sequence for $\mathrm{CO}_{2}$-PAN and S-PAN by the first-order Markov statistics are calculated. The pentad sequence of R-PAN has been proved to obey Bernoulli statistics by Kamide, ${ }^{11}$ because the summation of $P_{\mathrm{m} / \mathrm{r}}=0.519$, $P_{\mathrm{r} / \mathrm{m}}=0.481, P_{\mathrm{m}}=0.519$ and $P_{\mathrm{m} / \mathrm{m}}=0.519$, calculated by triad method is almost unity.

In the case of $\mathrm{CO}_{2}$-PAN (Table II), $\lambda$ for the $\mathrm{CO}_{2}$ PAN is 0.95 , which is almost approximately to 1 , it seems that the triad sequence of $\mathrm{CO}_{2}$-PAN obeys the Bernoulli statistics. Although $\delta$ value for Bernoulli statistics $\left(6.0 \times 10^{-3}\right)$ is a little higher than that for the first-order Markov statistics $\left(5.66 \times 10^{-3}\right)$, but the difference is not so significant, the difference can be negligible within the experimental uncertainty. So the pentad sequence of $\mathrm{CO}_{2}$-PAN seems to obey Bernoulli Statistics. Compared with the $\mathrm{CO}_{2}-\mathrm{PAN}$, there is not much difference between these values (i.e., $\lambda, \delta$ ) for the S-PAN, and then the pentad sequence of S-PAN can also be explained by Bernoulli statistics. For the Bernoulli statistics, the probability of tacticity propagation is independent of the stereochemical configuration of the propagation chain and reaction conditions (i.e., temperature, reaction time, $\mathrm{CO}_{2}$ pressure et al.)

We obtained $\mathrm{I}=0.153, \mathrm{H}=0.481, \mathrm{~S}=0.359$ for $\mathrm{CO}_{2}$ PAN. These values are different from those for S-PAN (i.e., $\mathrm{I}=0.27, \mathrm{H}=0.485, \mathrm{~S}=0.246$ ) and for R-PAN (i.e., $\mathrm{I}=0.269, \mathrm{H}=0.5, \mathrm{~S}=0.232$ ). From these results, for the S-PAN, the $(\mathrm{m})$ content is 0.51 , the $(\mathrm{mm})$ content 0.27 and the $(\mathrm{mmm})$ content 0.14 . And for the R-PAN, the $(\mathrm{m})$ content is 0.52 , the $(\mathrm{mm})$ content 0.269 , the $(\mathrm{mmm})$ content 0.14 . The S-PAN seems to have same stereoregularity as the R-PAN, but the stereoregularity of $\mathrm{CO}_{2}$-PAN is not the case, with the $(\mathrm{m})$ content 0.4 , the $(\mathrm{mm})$ content 0.153 and the $(\mathrm{mmm})$ content 0.057 , it lowers those of the S-PAN or R-PAN by aqueous phase radical polymerization methods by $22 \%, 43 \%$, and $59 \%$ respectively. Although the three kinds of PAN mentioned above all obey Bernoulli Statistics and they are all completely random in stereoregularity, the $\mathrm{CO}_{2}-$ PAN seems to have lower isotacticity than the other two kinds of PAN. The reason is probably due to different solvent system used. Since $\mathrm{CO}_{2}$ is non-polar, the

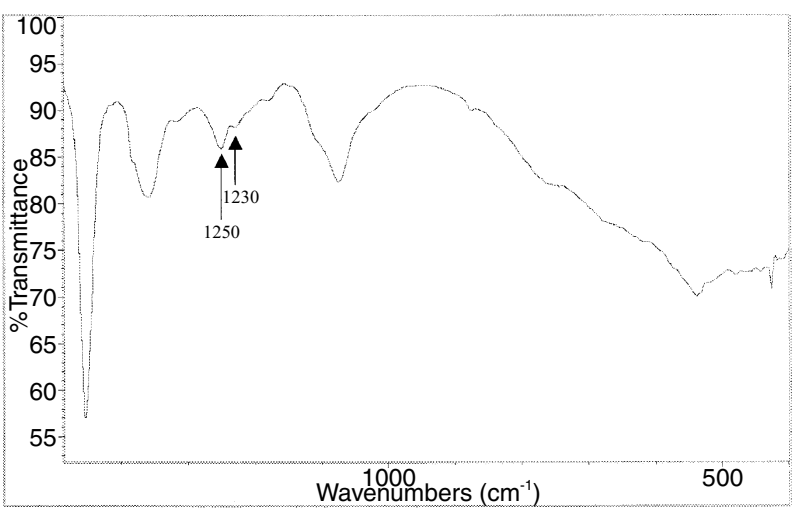

Figure 3. IR spectra of $\mathrm{CO}_{2}-\mathrm{PAN}$. Arrows indicate the IR characteristic bands, which are sensitive to stereoregularity of PAN.

polymerization in $\mathrm{CO}_{2}$ seems helpful to repulsion between cyano groups, which reduce the chance of meso sequence on the propagation chain.

Due to the interaction of solvent to polymer is dependent on polymer stereoregularity and the solvent power is related to the solvent ability to interact on the long meso (m) sequence part in PAN,${ }^{18}$ the lower isotactic $\mathrm{CO}_{2}$-PAN means that it has good dissolve ability in solvent, which is proved by being dissolved in DMF easily for wet-spinning, the mentioned work was appeared in our another research paper. ${ }^{8}$

\section{Intensity of IR Bands and Stereoregularity of PAN}

According to Minagawa, ${ }^{19}$ the IR spectroscopic features of stereoregular PAN appear in the absorption band near $1230 \mathrm{~cm}^{-1}$ and $1250 \mathrm{~cm}^{-1}$ (Figure 3). And the quantitative relationship to triad sequence length can be expressed in the following numerical form:

$$
Y=0.21+0.51 X
$$

Where $Y$ is the normalized IR intensity $\left(Y=S_{1230} /\right.$ $\left.\left(S_{1230}+S_{1250}\right)\right), S$ is integrated area of intensity) and $X$ is the fraction of isotactic triad units.

Table III shows comparison of triad isotactic of $\mathrm{CO}_{2}-$ PAN calculated by IR and ${ }^{13} \mathrm{C}$ NMR methods. The value 0.16 for IR and 0.153 for ${ }^{13} \mathrm{C}$ NMR are in good accordance within experimental error.

The detailed data on pentad tacticity of $\mathrm{CO}_{2}-\mathrm{PAN}$, presented here, will be helpful for a better understanding of polymerization mechanism in supercritical $\mathrm{CO}_{2}$. 


\section{CONCLUSION}

Compared with the aqueous suspension radical polymerization and the aqueous precipitation radical polymerization of AN, It was found that the sequence distributions of PAN obtained by precipitation polymerization in supercritical $\mathrm{CO}_{2}$ obeyed Bernoulli statistics and the stereoregularity of it was completely random, i.e., the $(\mathrm{m})$ content of $\mathrm{CO}_{2}$-PAN was about 0.4 , the $(\mathrm{mm})$ content 0.153 and the $(\mathrm{mmm})$ content 0.057 , which lowered those of the S-PAN or R-PAN by aqueous phase radical polymerization methods by $22 \%, 43 \%$, $59 \%$, respectively. The lower isotacticity of $\mathrm{CO}_{2}-\mathrm{PAN}$ may be due to the non-polar property of $\mathrm{CO}_{2}$. The triad isotacticity (i.e., the content of $\mathrm{mm}$ ) of $\mathrm{CO}_{2}$-PAN determined by IR method was good accordance with that ${ }^{13} \mathrm{C}$ NMR method.

Acknowledgment. This work is funded by the Ministry of Education, P. R. China.

\section{REFERENCES}

1. D. A. Canelas and J. M. DeSimone, Adv. Polym. Sci., 133, 103 (1997)

2. J. L. Kendall, D. A. Canelas, J. L. Young, and J. M. DeSimone, Chem. Rev., 99, 543 (1999).
3. J. M. DeSimone, Z. Guan, and C. S. Elsbernd, Science, 257, 945 (1992).

4. J. M. DeSimone, E. E. Maury, Y. Z. Meuceloglu, J. B. McClain, T. R. Romack, and J. R. Combes, Science, 265, 356 (1994).

5. H. Shiho and J. M. DeSimone, Macromolecules, 33, 1565 (2000).

6. K. Fuki, T. Kagiya, H. Yokota, Y. Toriuchi, and K. Fujii, U.S. Patent 3522 228, (July 28, 1970).

7. J. A. Hyatt, J. Org. Chem., 49, 5097 (1984).

8. X. Teng and X. Hu, J. Appl. Polym. Sci., (in press).

9. X. Teng, H. Shao, and X. Hu, J. Appl. Polym. Sci., (in press).

10. H. Balard and J. Meybeck, Eur. Polym. J., 13, 611 (1977).

11. K. Kamide, H. Yamazaki, K. Okajima, and K. Hikichi, Polym. J., 17, 1291 (1985).

12. K. Kamide, H. Yamazaki, K. Okajima, and K. Hikichi, Polym. J., 17, 1233 (1985).

13. K. Kamide, H. Yamazaki, K. Okajima, and K. Hikichi, Polym. J., 18, 277 (1986).

14. K. Kamide, H. Ono, and K. Hisatani, Polym. J., 24, 917 (1992).

15. F. A. Bovey, "Polymer Conformation and Configuration", Academic Press, Inc., New York, N.Y., 1967.

16. H. L. Frisch, C. L. Mallows, and F. A. Bovey, J. Chem. Phys., 45, 1565 (1966).

17. H. L. Frisch, C. L. Mallows, F. Heatley, and F. A. Bovey, Macromolecules, 1, 533 (1968).

18. M. Hattori, H. Yamazaki, M. Saito, K. Hisatani, and K. Okajima, Polym. J., 28, 594 (1996).

19. M. Minagawa, K. Miyano, M. Takahashi, and F. Yoshii, Macromolecules, 21, 2387 (1988). 